This item was submitted to Loughborough's Research Repository by the author.

Items in Figshare are protected by copyright, with all rights reserved, unless otherwise indicated.

\title{
Influence of short rear end tapers on the unsteady base pressure of a simplified ground vehicle
}

PLEASE CITE THE PUBLISHED VERSION

http://dx.doi.org/10.427/2016-01-1590

PUBLISHER

(C) SAE International

VERSION

VoR (Version of Record)

\section{PUBLISHER STATEMENT}

This work is made available according to the conditions of the Creative Commons Attribution-NonCommercialNoDerivatives 4.0 International (CC BY-NC-ND 4.0) licence. Full details of this licence are available at: https://creativecommons.org/licenses/by-nc-nd/4.0/

\section{LICENCE}

CC BY-NC-ND 4.0

\section{REPOSITORY RECORD}

Pavia, Giancarlo, Martin A. Passmore, and Adrian P. Gaylard. 2016. "Influence of Short Rear End Tapers on the Unsteady Base Pressure of a Simplified Ground Vehicle”. figshare. https://hdl.handle.net/2134/21524. 


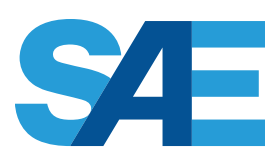

INTERNATIONAL。

\section{Influence of Short Rear End Tapers on the Unsteady Base Pressure of a Simplified Ground Vehicle}

\section{Giancarlo Pavia and Martin Passmore}

Loughborough University

\section{Adrian Gaylard}

Jaguar Land Rover

CITATION: Pavia, G., Passmore, M., and Gaylard, A., "Influence of Short Rear End Tapers on the Unsteady Base Pressure of a Simplified Ground Vehicle," SAE Technical Paper 2016-01-1590, 2016, doi:10.4271/2016-01-1590.

Copyright (C) 2016 SAE International

\begin{abstract}
Short tapered sections on the trailing edge of the roof, underside and sides of a vehicle are a common feature of the aerodynamic optimization process and are known to have a significant effect on the base pressure and thereby the vehicle drag. In this paper the effects of such high aspect ratio chamfers on the time-dependent base pressure are investigated. Short tapered surfaces, with a chord approximately equal to $4 \%$ of the overall model length, were applied to the trailing edges of a simplified passenger car model (the Windsor Body) and base pressure studied via an array of surface pressure tappings. Two sets of configurations were tested. In the first case, a chamfer was applied only to the top or bottom trailing edge. A combination of taper angles was also considered. In the second case, the chamfer was applied to the side edges of the model base, leaving the horizontal trailing edges squared. In all configurations both the base and the slanted surfaces were covered with pressure taps for the entire width to ensure that any asymmetry was captured and two different sampling time were considered (respectively equal to $31.5 \mathrm{~s}$ and $630.0 \mathrm{~s}$ ). The results show the effects produced on the base pressure by the presence of a long period bi-stable behavior, whose characteristics were further investigated by conditional averaging the recorded data and considering the distribution of the rms pressure values recorded over the entire model base.
\end{abstract}

\section{Introduction}

In the last few decades stricter homologation requirements in terms of $\mathrm{CO}_{2}$ emissions have led the main car manufacturers to concentrate their efforts in reducing the fuel consumption of new vehicles. This goal has been mainly pursued through the adoption of more efficient powertrains, including down-sized internal combustion engines, hybrid systems and full electric vehicles.

These new powertrain systems however require major investment in research and development and create new problems in terms of added weight and complexity and, in the case of fully electric vehicles, limited range. For these reasons, many OEMs are also focusing on the reduction of vehicle mass by using lightweight materials and weight saving building techniques, together with the cut of vehicle losses by means of development of fuel saving tires, with lower rolling resistance, and reductions in aerodynamic drag. The latter is particularly important because at motorway speeds the aerodynamic drag represents by far the main source of losses for any ground vehicle, regardless of the nature of its powertrain. In addition, the aerodynamic characteristics of a passenger car, particularly the unsteady ones, can affect other attributes of the car such as the straight-line stability (especially in crosswind conditions) and the passengers' aero-acoustic comfort (particularly so for low-noise powertrains, such as electric vehicles). The unsteady effects become increasingly important when also combined with reductions in vehicle mass.

The use of squareback geometry is common in the automotive industry, being the shape that characterizes the rear ends of hatchbacks and estate cars and most SUVs and commercial vehicles. The wake generated by these vehicles is dominated by the presence of a large region of separation that results in a large contribution to the resistance through an increase in the pressure drag. The wake is contained by four shear layers emanating from the vehicle sides, roof and underbody and has been shown to have a characteristic toroidal shape in steady state as showed by Krajnović and Davidson [1], for a bus-shaped body, and [2] Roumeas et al., for a squareback Ahmed Body [ $\underline{3}]$. This circular vortex ring is the source of significant pressure losses and interacts with the main flow in the longitudinal direction until a pair of counter-rotating longitudinal vortices is formed downstream of the near wake region.

It is widely accepted that the base drag caused by this wake structure can be reduced by manipulating its shape and size, for example using passive control techniques such as geometrical changes [4]], streamwise streak generators []ㅡ and flaps applied to the rear-end of simplified vehicle models []]. Or alternatively using active flow control techniques, such as suction [7]], blowing [ㅁ] and oscillating suction and blowing [9]. The results from such active systems suggest they can be effective in manipulating the wake structure with minimal 
impact on the external shape of the vehicle, but the reduction in drag is often outweighed by the increase in the vehicle mass and the energy input required to operate them.

A first attempt to achieve a drag reduction by applying a high aspect ratio slant to the roof trailing edge of a squareback model was done by Littlewood and Passmore [10]. It was found that the application of a $12^{\circ}$ slant resulted in a drag reduction of $2.7 \%$; achieved through an increase in the base pressure greater than the suction acting on the slanted surface. For values of the slant angle greater than $12^{\circ}$, however, this suction force was found to outweigh the base drag growth, yielding an increase of the overall drag. Most recently, Perry et al. [11] investigated the effects produced by similar slants applied to both the two horizontal trailing edges and to the side trialing edges of a similar model. In the first case it was noticed that, applying the top and bottom tapers asynchronously, the interactions between the upwash and the downwash had a large effect on the base pressure distribution and the minimum drag value was achieved with a $16^{\circ}$ top edge taper and a $6^{\circ}$ bottom edge taper in place. The application of side edge tapers resulted in a change in the dimension of the side lobes of the wake torus, leading to an even higher drag reduction, with the lowest drag value recorded with the application of a chamfer angle equal to $12^{\circ}$.

The literature successfully demonstrates the effects produced on the base drag by relatively small geometrical changes, but focuses only on the time averaged results (typically averaged over $30 s$ ) and, when measuring base pressure, they considered only half of the model base, assuming symmetry between the two sides of the model wake. Work by Grandemange et al. [12], however, pointed out the existence of a bi-stable behavior in the wake of a $1 / 4$ version of an Ahmed Body with very long time scales ( $t_{s} \square 10^{3} \mathrm{H} / U_{0}, \mathrm{H}$ being the height of the model and $U_{0}$ the free stream velocity). It was noticed that this behavior is characterized by a random shift between two preferred symmetry breaking states, leading to a statistically symmetric wake. In addition, it was proved that this phenomenon is purely random and behaves like a stationary Markov chain, resulting in an unsteady side force that was found to be responsible for part of the drag experienced by the model.

In a further study, Grandemange et al. [13] analyzed the sensitivity of this particular bi-stable behavior to ground proximity and the base aspect ratio. They found the bi-stability vanishes when the ground clearance is small enough to promote the detachment of the underbody flow on the ground. But, otherwise the wake showed a bistable motion in the lateral direction, for values of the model width $W$ greater than the model height $H$, and in the vertical direction when $H>W$. The wall proximity, however, is not shown to stabilize the flow, since in the same experiment the wake showed a bi-stable nature along the lateral direction when the value of the model ground clearance was set to zero.

A similar result was also found by Herry et al. [14] for the wake past a $3 \mathrm{D}$ backward facing step, at Reynolds number between $5 \times 10^{3}$ and $8 \times 10^{4}$ (based on the first step height). At zero degree yaw angle the wake showed a bi-stable behavior that was described by the authors as a critical case where the flow switches randomly between two different solutions, related respectively to positive and negative values of the yaw angle.
The same conclusions were also reached by Volpe at al. [15], performing a series of wind tunnel tests for a full scale Ahmed Body at two different height based Reynolds numbers (respectively equal to $5.1 \times 10^{5}$ and $7.7 \times 10^{5}$ ). By using a series of conditionally averaged PIV fields and base pressure data, they isolated the two states both for the wake topology and pressure distribution over the model base. In addition, considering the temporal distribution of the two stable positions, they highlighted the sensitivity of bi-stability to the yaw angle, as proved by the fact that when a yaw angle of $0.4^{\circ}$ was imposed a $70 \%$ predominance of one of the two states was encountered.

In more recent work [16], Grandemange et al. found the same behavior when investigating the wake produced by an Ahmed Body scaled to a full size small car, (4 times the scale of the original model used in [ $\underline{3}]$ ), equipped with rotating wheels and tested using a full scale industrial facility giving a Reynolds number of $2.5 \times 10^{6}$, based on the model height. Measuring the aerodynamic forces for the squareback configuration, they noticed that the drag remained constant for yaw angles within the interval $\pm 0.5^{\circ}$, for which the side force displayed very large fluctuations. They ascribed this particular trend to the bi-stable nature of the wake and pointed out that the same trend was still visible for the optimal drag configuration obtained by chamfering the model horizontal trailing edges, which resulted in a $5.8 \%$ drag reduction over the squareback configuration for top and bottom chamfers angles respectively equal to $7.5^{\circ}$ and $5.0^{\circ}$. For this last configuration, a further $1.6 \%$ drag improvement was achieved by suppressing the wake bi-stability using a small vertical cylinder placed at the center of the recirculation region, as this technique had already proved to be successful in preventing the switch between the two sates in a scale down version of the same model [17]. Another efficient method for the inhibition of the wake bi-stability was found with the application of a $100 \mathrm{~mm}$ long cavity behind the model that, together with the tapering of all the four trailing edges, brought a drag reduction of $10.7 \%$.

The long time bi-stable nature of the wake could also explain the asymmetry that characterizes the time averaged flow field past a simplified notchback geometry (for values of the effective backlight angle several degrees below the non-reattachment condition) investigated both experimentally and numerically by Sims-Williams et al. [18] and Krajnović and Minelli [19] and could be responsible for the fluctuations in the aerodynamic load under steady-state conditions described by Kawakami et al. [20] for a stock hatchback car model.

The purpose of the present paper is to further investigate the wake bistability by considering a model that, although being still fairly simple, is characterized by a front-end whose shape is more similar to that of a real passenger car than the Ahmed Body used in [12], [15] and [16] and also by a central section whose length is more representative of that seen in real vehicles. The effects produced by bi-stability on base pressure will be analyzed, with a particular emphasis on the effects produced by the application of top-bottom and side edge tapers both on the time averaged and fluctuating pressure field. 


\section{Experimental Procedure}

\section{The Model}

The experiment was carried out with the Windsor Model, already used by Littlewood and Passmore [10] and Perry et al. [11]. The model has an overall length $L$ of $1044 \mathrm{~mm}$, a width $H$ of $389 \mathrm{~mm}$ and a height $H$ of $289 \mathrm{~mm}$. Its main dimensions are similar to the model considered by Ahmed et al. in [ $\underline{3}]$ and make it representative of an approximately $1 / 4$ scale passenger car. In order to avoid flow separation, its front-end features rounded leading edges, with radii of $50 \mathrm{~mm}$ on the nose and $200 \mathrm{~mm}$ on the roof.

During the tests, the model was placed on a circular turntable and supported by four M8 threaded bars, situated in locations representative of the front and rear axles, $10 \mathrm{~mm}$ inboard from the model sides. Both the model and the turntable were connected to a yaw drive system which allowed the model to be rotated around its vertical axis (defined according the MIRA co-ordinate system), changing therefore the aerodynamic yaw angle, with an accuracy of $\pm 0.02^{\circ}$. All the tests were performed considering a ground clearance $h$ of $50 \mathrm{~mm}$, corresponding to a normalized value $\left(h^{*}=h / H\right)$ of 0.17 (considering the vehicle height as reference length) that is representative of the ride height typical of crossovers and small SUVs.

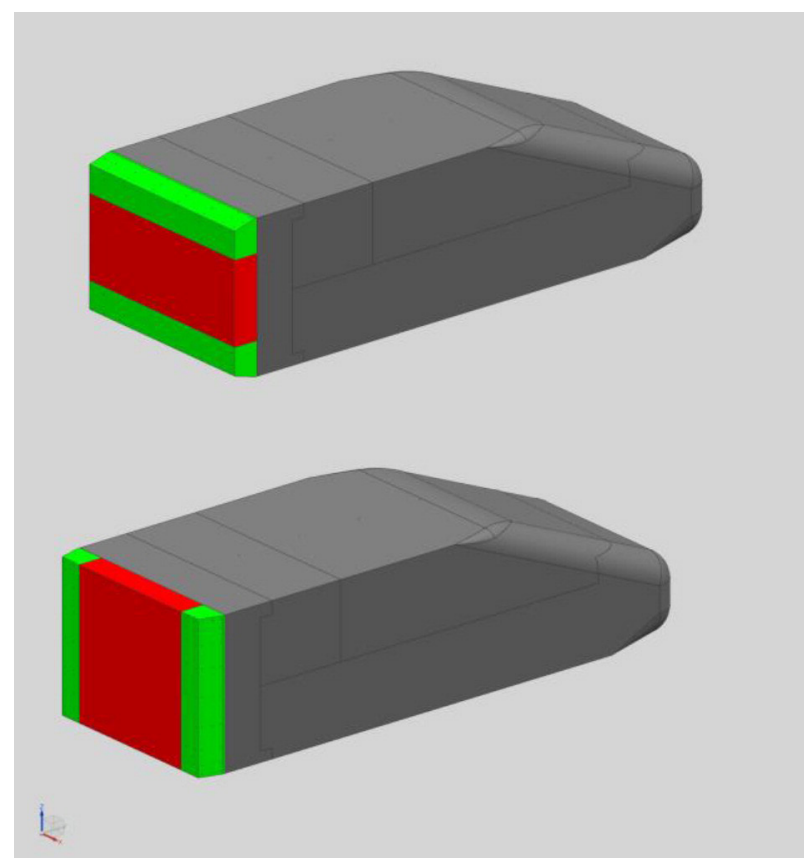

Figure 1. Representation of the Loughborough University Windsor Body with the two tested rear-end configurations.

The model was manufactured by using polyurethane machinable slabs and has multiple rear inserts to allow the testing of the different rear slant angles considered in the present work. As in [11], all the tapers have a length of $45 \mathrm{~mm}$. Slant angles of $0^{\circ}, 6^{\circ}, 12^{\circ}, 16^{\circ}, 20^{\circ}$ were considered both for the horizontal and vertical trailing edges, together with two different rear sections in order to allow the fitting of the horizontal and vertical tapers (as shown in Figure 1). These values were chosen since they are representative of aerodynamic behavior of the slanted surface, which is characterized by the presence of a suction region close to the taper leading edge whose extension increases with the chamfer angle until a critical angle is reached (Perry et al. in [11]). Beyond this, the flow fully separates from the tapered surface, increasing the pressure acting on the surface itself.

\section{The Test Facility}

The experiments were carried out in the Loughborough University Wind Tunnel, whose description can be found in [21]. The tunnel has an in-draft configuration (see Figure 2), with a $2.5 \mathrm{~m}^{2}$ working section cross sectional area, resulting in a blockage ratio of $4.4 \%$ with the Windsor Body employed here. The flow speed was set at $40 \mathrm{~m} / \mathrm{s}$, corresponding to the normal tunnel operating velocity; the resultant Reynolds number is therefore $7.7 \times 10^{5}$ (based on the model height). Free-stream turbulence intensity is approximately $0.2 \%$ and flow uniformity equal to $\pm 0.4 \%$.

The tunnel is not equipped with a moving ground plane but the non-dimensional ground clearance considered in the present work $\left(h^{*}\right.$ $=0.17$ ) was sufficient to avoid effects such as floor boundary layer separation and diffuser blockage that could have significantly affected the pressure distribution over the model base (Cooper et al. [22]).

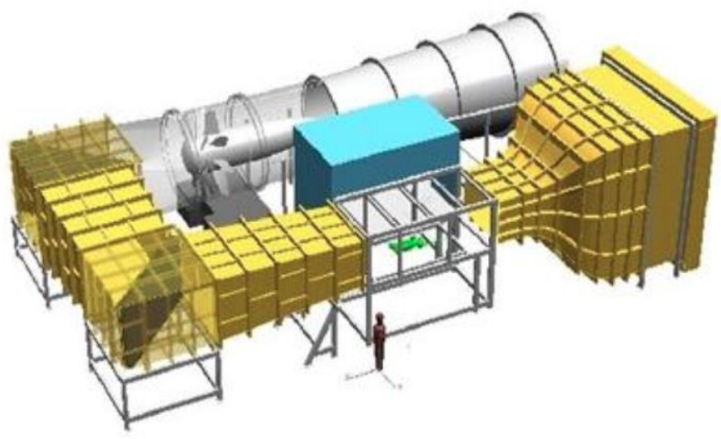

Figure 2. The Loughborough University Wind Tunnel. Sketch from [21].

\section{Pressure Measurements}

The pressure acting on the model rear facing surfaces was recorded by populating the base and the tapers with a grid of pressure tappings, consisting of $25 \mathrm{~mm}$ long brass tubes with an internal diameter of 0.9 $\mathrm{mm}$, mounted flush to the surface and connected via flexible tubes to a pair of 64 channel miniature pressure scanners with a manufacturer quoted accuracy of $\pm 1.47 \mathrm{~Pa}$. In the first case (with the horizontal tapers in place) 120 tappings were used and in the second case (with the vertical tapers applied to the model base) 126 . In both the cases, the tappings were placed across the whole width of the base, with a finer distribution close to the edges in order get a more accurate representation of the pressure distribution in the region with the highest gradients (as shown in Figure 3).

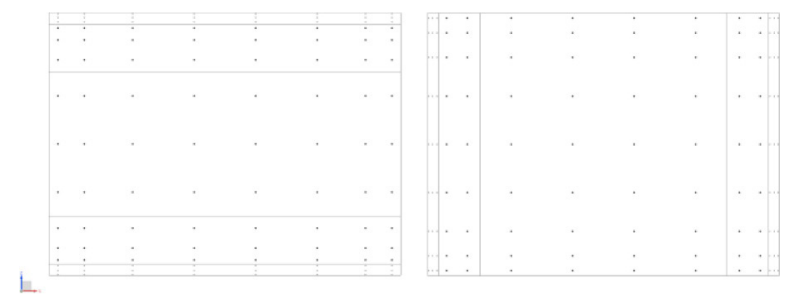

Figure 3. Pressure tapping grids used for the two different configurations. 
Pressure samples were collected at $260 \mathrm{~Hz}$, for two different sampling times $T_{S}$, respectively equal to $31.5 \mathrm{~s}$ and $630.0 \mathrm{~s}$. Pressure signal distortion caused by the tubes connecting the model surface to the pressure scanners was removed using the same experimentally derived correction function proposed by Sims-Williams and Dominy in [르 and implemented by Wood et al. in [24].

In the present work, the results will be presented in terms of pressure coefficient values $C_{p}$, based on the free-stream dynamic pressure recorded at the entrance of the working section. All the results have been corrected for blockage using the MIRA correction (based on continuity) expressed in Equation 1 (where B denotes the blockage value, given by the ratio between the model frontal area and tunnel working section cross sectional area).

$$
1-C_{p_{\text {corr }}}=\left(1-C_{p}\right)(1-B)^{2}
$$

\section{Results and Dicussion}

\section{Squareback Configuration}

For the squareback configuration, two different sampling times were considered, corresponding to $T_{S}=31.5 \mathrm{~s}$ and $T_{S}=630.0 \mathrm{~s}$.

For a sampling time of $31.5 \mathrm{~s}$ (see Figure 4(a)), the time averaged results show the existence of two distinctive regions over the model base, with the left-hand side characterized by a lower pressure than the right-hand side. The overall pressure field, indeed, seems to be dominated by a strong gradient along the horizontal direction, which would have been expected only in the presence of a non-zero yaw angle. The highest level of pressure fluctuations (Figure 4(b)) is located in the region when the transition between low pressure and high pressure occurs.

Time Averaged $\mathrm{C}_{\mathrm{p}}$

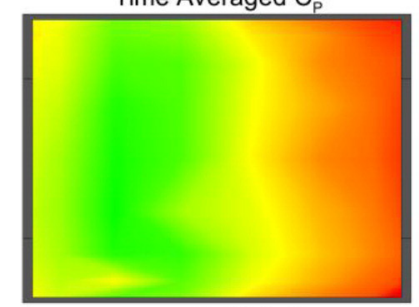

$\psi=0.0^{\circ}(\mathrm{a})$

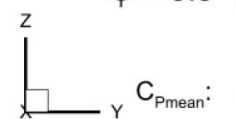

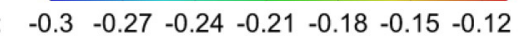

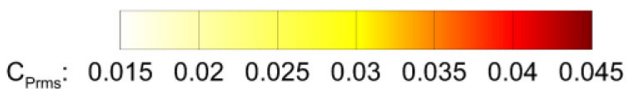

Figure 4. Squareback configuration: time averaged and fluctuating pressure distribution over the model base $\left(T_{S}=31.5 \mathrm{~s}\right)$.

The topology of the pressure distribution changes significantly with a longer sampling time (see Figure 5(a) where $T_{S}=630.0$ ) becoming very similar to that reported in [12] and [15] for a squareback Ahmed Body. With the large sampling time the pressure map is characterized by a good level of symmetry between the two sides of the base. In particular, the results show the presence of a fairly big region of low pressure acting on the inner zone of the rear facing surface, surrounding an area with slightly higher values of $C_{p}$ located close to the center of the base itself. A pressure increase can be also noticed towards the side trailing edges, with the highest value of static pressure recorded by the taps placed closest to the edges themselves.

These results seem to indicate for this case the existence of the toroidal structure already proposed by [2] for the steady near wake past a squareback Ahmed Body. The inner region of high pressure, indeed, can be associated with the reverse flow impinging on the base, as shown for example by the LDA results obtained by Strachan et al. in [25]. In addition, the fact that this high pressure region is slightly closer to the bottom trailing edge than the top trailing edge seems to suggest the presence of a deformation in the lower lobe of the torus due to ground proximity, in analogy with the results obtained in [25] with a moving ground system. The aforementioned low pressure zone, instead, can be considered the consequence of the tangential flow acting on the base due to its interaction with the external surface of the torus, as already pointed out by Littlewood et al. in [26].

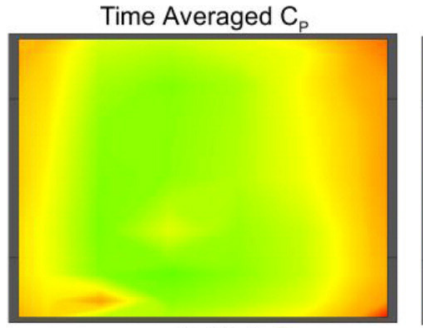

$\psi=0.0^{\circ}(\mathrm{a})$

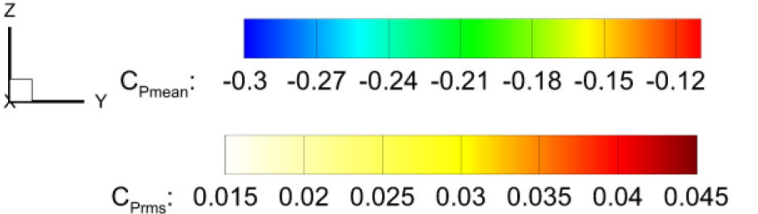

Figure 5. Squareback configuration: time averaged and fluctuating pressure distribution over the model base $\left(T_{S}=630.0 \mathrm{~s}\right)$.

The distribution of the $C_{P_{\text {rms }}}$ values (Figure 5(b)) shows the presence of a level of unsteadiness higher than that seen with the shorter sampling time, with the existence of two peaks located in the middle of each half of the base. The overall topology matches very well the results obtained by Volpe et al. in [15], suggesting the existence of a long time scale coherent motion of the wake in the horizontal direction for the model considered in the present experiment. This mode seems to involve a random switch in the pressure recorded by each tap between two stable values and this is illustrated for a number of tappings in Figure 6. 


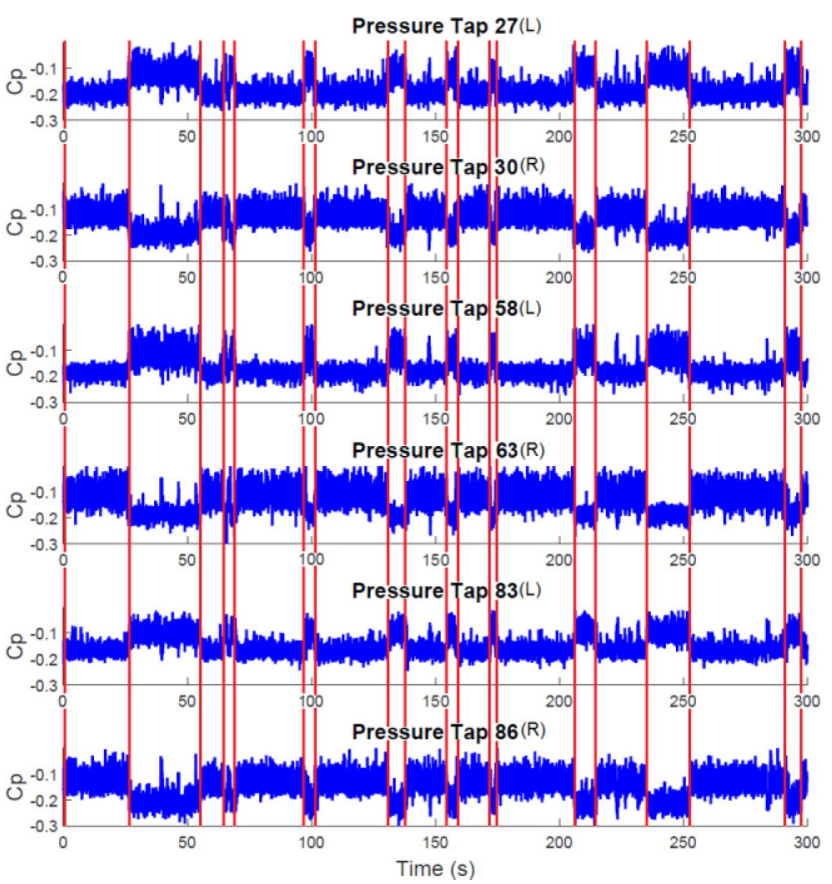

Figure 6. Squareback configuration: temporal trend of the $C_{p}$ recorded by some of the taps (shown in Figure 5b) placed around the region of high unsteadiness.

The switch between these two states appears to be purely random (as observed by Grandemange et al. [12]) and the changes in the pressure recorded by the taps seem to be in phase opposition between the two opposite sides of the base. Furthermore, the same plot shows that this change occurs with perfect synchronism between the tappings placed inside the region with the highest $C_{P_{r m s}}$, suggesting the existence of a coherent motion that involves most of the wake.

Although in [12] and [15] it has been proven that this phenomenon is purely random, an estimation of the mean duration $t_{s}$ of the stable states can still be useful to characterize its timescale. For this reason, the original set of data was resampled at $1 \mathrm{~Hz}$, in order to make the result comparable with those reported in literature. In the present case this produces a mean of $t_{S}=11.32 \mathrm{~s}$, which is close to that reported by Volpe et al. in [15] at the same Reynolds number and confirms the relation $t_{s} \square 10^{3} \mathrm{H} / \mathrm{U}_{0}$, proposed by Grandemange et al. in [12].

Volpe et al. in [15], also suggests that a useful way to visualize the two distinct stable positions that characterize the pressure field is to perform a conditional average of the unsteady data. In this case, the pressure values recorded by all the pressure tappings were sorted into two groups, according to the sign of the Equation 2:

$$
\Delta C_{P_{C A}}(\mathrm{t})=C_{P}\left(P_{r m s}^{R}, \mathrm{t}\right)-C_{P}\left(P_{r m s}^{L}, \mathrm{t}\right)
$$

where $P_{r m s}^{L}$ and $P_{r m s}^{R}$ are the taps with the highest level of pressure fluctuation respectively on the left-hand side and the right-hand side of the base. The results are presented in Figure 7.

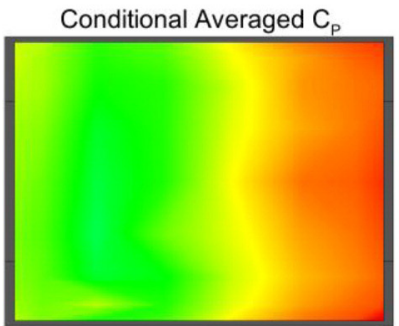

L State (a)

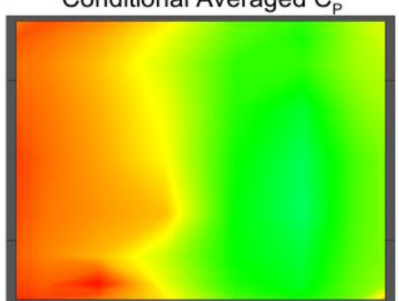

R State (b)

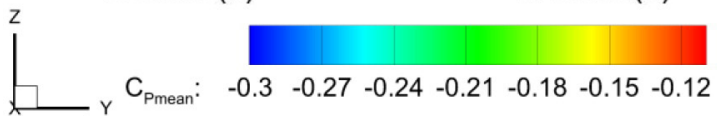

Figure 7. Squareback configuration: conditional averaged pressure fields.

Both the states show a strong asymmetry in the horizontal direction and appear to complement one another. In particular, the first pressure field, corresponding to $\Delta C_{P_{C A}}(\mathrm{t})>0$, shows a large region of low pressure acting on the left-hand side of the base ( $L$ state), whereas the second one, for $\Delta C_{P_{C A}}(t)<0$, is characterized by the presence of the low pressure region on the right-hand side ( $R$ state).

A further proof of the complementary nature of these two states is given by the values of the base $\operatorname{drag} C_{D_{\text {Base }}}$ associated with them, where $C_{D_{\text {Base }}}$ is estimated by means of Equation 3:

$$
C_{D_{\text {Base }}}=\frac{1}{S} \iint C_{P} \mathrm{~d} S
$$

being $S=0.112 \mathrm{~m}^{2}$ the frontal area of the model and $d S$ the geometric area associated with each tapping, projected in the longitudinal direction.

The application of this formula to the data referring to the time averaged field (for both the short and the long sampling time) and each of the two states yields the values for the base drag reported in Table. 1.

Table 1. Squareback configuration: effect of bi-stability on base pressure drag.

\begin{tabular}{|c|c|}
\hline & $\boldsymbol{C}_{\boldsymbol{D}_{\text {Base }}}$ \\
\hline Time Averaged Field $\left(\boldsymbol{T}_{\boldsymbol{S}}=\mathbf{3 1 . 5} \mathbf{\mathrm { s }}\right)$ & 0.162 \\
\hline Time Averaged Field $\left(\boldsymbol{T}_{S}=\mathbf{6 3 0 . 0} \mathbf{s}\right)$ & 0.163 \\
\hline L State & 0.163 \\
\hline R State & 0.164 \\
\hline
\end{tabular}

The results differ by no more than one count, suggesting the absence of a noticeable effect of the wake bi-stability on the integrated base pressure drag.

Since each of the two states is characterized by a strong left-to-right asymmetry, a study of the sensitivity of the bi-stability to small variation in the model yaw angle was carried out. A yaw sweep between $-0.5^{\circ}$ and $+0.5^{\circ}$ was performed, with steps of $\pm 0.1^{\circ}$ and a sampling time of $630.0 \mathrm{~s}$. The results obtained for $\Psi=-0.5^{\circ},-0.2^{\circ}$, $+0.2^{\circ},+0.5^{\circ}$ are presented in Figure 8 . They show the progressive growth of a lateral asymmetry in the time averaged pressure distribution as the magnitude of the yaw angle is increased. This suggests that as $\Psi$ moves away from zero, one of the two states is selected and its occurrence becomes more probable than that of the other state, until it remains almost the only admissible condition for 
values of $|\Psi|$ greater than $0.5^{\circ}$. At this point, the time averaged pressure maps resemble those already obtained by conditional averaging the pressure field for $\Psi=0.0^{\circ}$, and the flow field behind the model looks more stable, as underlined by the noticeable reduction in the fluctuation of the static pressure over the base.

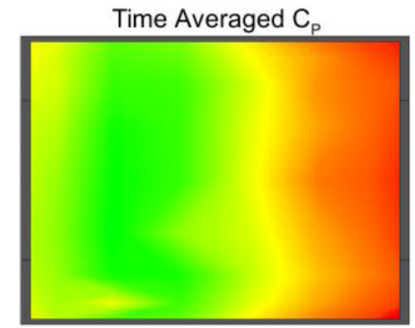

$\psi=-0.5^{\circ}(\mathrm{a})$

Time Averaged $C_{p}$

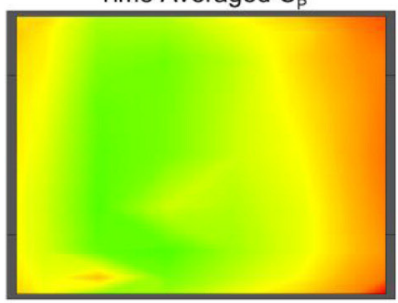

$\psi=-0.2^{\circ}(\mathrm{c})$

Time Averaged $\mathrm{C}_{\mathrm{p}}$

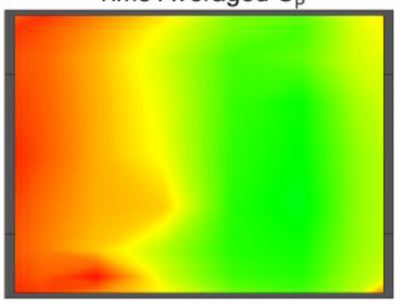

$\psi=+0.2^{\circ}(\mathrm{e})$

Time Averaged $\mathrm{C}_{\mathrm{p}}$

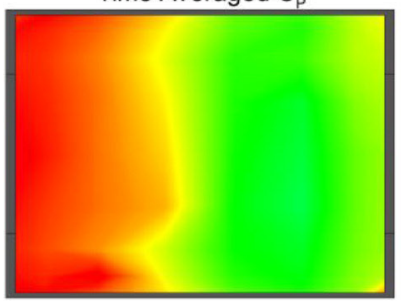

$\psi=+0.5^{\circ}(\mathrm{g})$

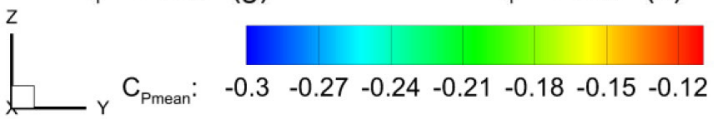

$C_{P_{\text {Prms }}:}: \begin{array}{lllllll}0.015 & 0.02 & 0.025 & 0.03 & 0.035 & 0.04 & 0.045\end{array}$

Figure 8. Squareback configuration: time averaged and fluctuating pressure distribution over the model base for different yaw angles $\left(T_{S}=630.0 \mathrm{~s}\right)$.

This trend is further confirmed by looking at the evolution, for the same yaw angles, of the probability density function (PDF) of the pressure coefficients recorded by the tap with the highest $C_{P_{r m s}}$ in the zero yaw condition (Figure 9 ). This plot shows the existence of a clear bi-modal distribution at $\Psi=0^{\circ}$, with two distinct peaks associated with the two states previously described.

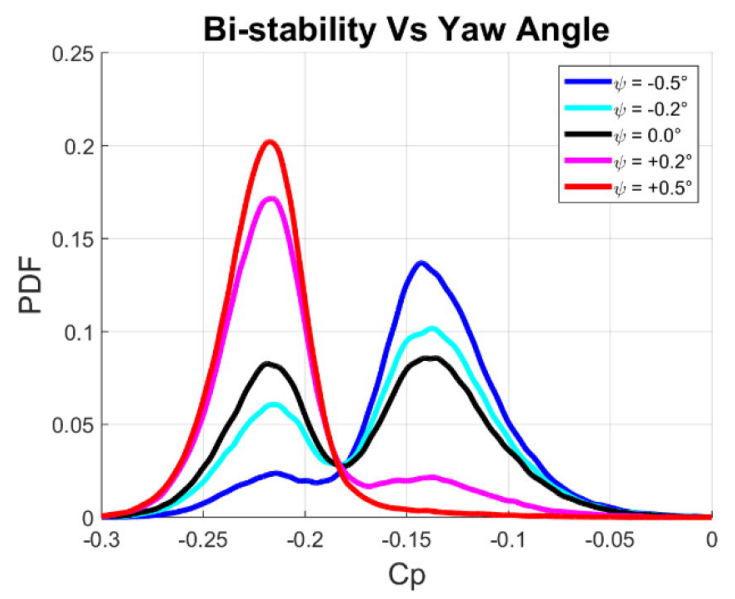

Figure 9. Squareback configuration: probability density function of the pressure recorded at different yaw angles by the tap with the highest value of $C_{P_{r m s}}$ for $\Psi=0.0^{\circ}$.

As the yaw angle is moved away from zero, the probability of one of the two states starts to increase at the expense of the other, until an almost normal distribution, with a single well-defined peak, is reached for values of the yaw angle around $\left|0.5^{\circ}\right|$. This last aspect, is still in good agreement with the results of the findings of Volpe al. [15], suggesting the existence of a similar behavior of the bi-stable mode to small changes in the yaw angle, despite the different shape of the fore-body of the models considered in the two experiments.

Furthermore, this highlights the fact that the bi-stability is a phenomenon that is limited to the wake, as suggested by Grandemange et al. in [12].

\section{Horizontal Tapers}

The effects produced on base pressure and wake bi-stability by the application of high aspect ratio tapers to the model horizontal trailing edges were studied by separating the contribution of the top taper from the bottom one and reporting the results in detail. As their effect on the behavior of the overall wake cannot be simply superimpose, (Perry et al. in [11]) an additional configuration showing the combined effect of a top and bottom chamfer is also considered.

\section{Top Taper}

In the first case, the value of the bottom taper angle $\Phi_{B}$ was fixed at $0^{\circ}$ and the chamfer angle at the top trailing edge $\Phi_{T}$ was increased to $6^{\circ}, 12^{\circ}, 16^{\circ}$ and $20^{\circ}$. The aspect ratio of the slant is 8.66 (based on the model width).

The results in terms of time averaged pressure field and its fluctuations are presented in Figure 10. Looking at the time averaged data (see Figure 10(a,c,e,g)), it is easy to notice how the presence of the tapered surface can induce significant changes in the distribution of the static pressure acting on the model rear facing surfaces, suggesting a mutation in the topology of the near wake. The top taper turns the flow over the roof towards the ground generating a downwash effect that counteracts the ground proximity effect already mentioned for the squareback case. This leads to the growth of the top and side lobes of the torus, whose cross sections tend to be more uniform, increasing the amount of reverse flow that impinges on the base in the normal direction and therefore the static pressure in the inner region of the base itself. At the same time, the wake is moved 
downstream, so that the interaction between the toroidal structure and the model rear surface is limited and the resulting region of low pressure reduced, in agreement with the results of the simulation performed by Khalighi et al. in their study of the effects produced by the boat-tailing of a simplified bluff body [27].

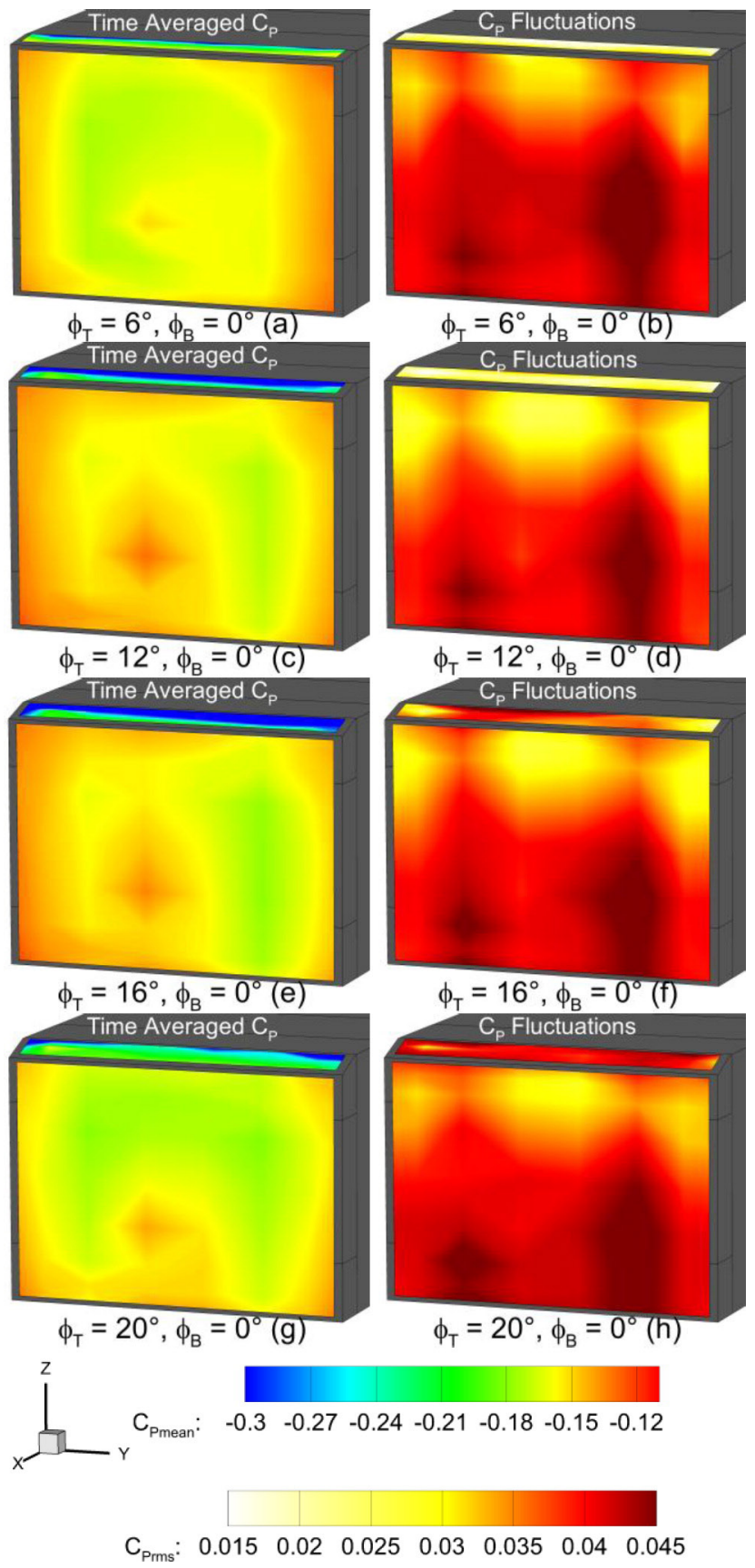

Figure 10. Time averaged and fluctuating pressure distribution over the model base for different top taper angles $\left(T_{S}=630.0 \mathrm{~s}\right)$.

As the taper angle is increased, this phenomenon yields a reduction in the base drag, until a minimum is reached for $\Phi_{T}=12^{\circ}$ (see Figure 12), with a trend that is similar to the drag results recorded for the same configuration by Perry et al. in [11]. Beyond this value, the base drag starts to rise again, following the widening of the low pressure region in the upper half of the base shown in Figure 10e and Figure $10 \mathrm{~g}$. This behavior can be justified assuming an excessive growth of the upper section of the torus due to the flow entrained by the taper into the top recirculation zone, which results in an increase of the tangential component of the velocity acting on the base and then a reduction of the pressure over the model rear end. This process is sufficiently strong that does not seem to be affected by the "stall" of the tapered surface, highlighted by the sudden reduction of the suction acting on this surface for slant angles greater than $16^{\circ}$.

In these conditions, the presence of fully separated flow over the tapered surface is clear looking at the unsteady pressure fields, reported in Figure $10(\mathrm{~b}, \mathrm{~d}, \mathrm{f}, \mathrm{h})$. For values of $\Phi_{T}$ up to $12^{\circ}$, the pressure field over the slant shows a low level of unsteadiness, especially if compared to the bottom of the model base. However, above this angle, the level of fluctuations starts to increase, especially close to the taper leading edge, until reaching its maximum for $\Phi_{T}=$ $20^{\circ}$.

This phenomenon is not limited to the taper but seems also to have consequences on the unsteady pressure field acting over the entire model base. The downwash created by the top slanted surface, indeed, leads to a shift of the region with the highest values of $C_{P_{r m s}}$ (associated with bi-stability) towards the bottom trailing edge, with the appearance of three zones of low unsteadiness close to the top edge of the base. In particular, the first two regions are placed close to the tips of the taper, in the same zones where the longitudinal trailing vortices created by the slant (as already shown by the PIV results obtained by Howell et al. in [28] for a similar configuration) are expected to interact with the near wake recirculation. The third region of low unsteadiness, is positioned close to the middle of the taper trailing edge, where the amount of flow deflected by the taper into the model wake reaches its maximum. It is interesting to note how these zones tend to change their size simultaneously with the chamfer angle, further confirming the fact that they are the result of the interaction between the flow deflected by the taper and the wake structure previously described. At the same time, the variation of their dimensions is accompanied with an opposite change in the size of the bi-stable region. For values of $\Phi_{T}$ between $6^{\circ}$ and $12^{\circ}$, the increase in the suction over the taper leads to a strengthening of the tip vortices and an increase in the amount of flow deflected into the wake. As a consequence, the upper part of the wake appears to be stabilized, and the shift between the two states are limited to the lower part of the model rear-end, where the longitudinal tip vortices and the recirculation bubble are expected to be weaker than in the upper region due to the absence of the cross-flow generated by the slanted surface. However, once the flow over the slant is fully separated, the strength of the tip vortices is reduced and the taper itself is less effective in deviating the flow into the near wake. Therefore, the upper lobe of the torus becomes less stable and the extension of the bi-stable zone increases again.

The downwash induced by the taper seems to also affect the probability of the switch between the two bi-stable states; this is seen in the plot reported in Figure 11, showing the PDF of the normalized pressure recorded by the tap on the model base with the highest $C_{P_{r m s}}$, for three different values of $\Phi_{T}\left(6^{\circ}, 12^{\circ}, 20^{\circ}\right)$. Here an increase in the taper angle from $6^{\circ}$ to $12^{\circ}$ seems to promote the selection of one of the two states, resulting in a lower degree of bimodality. However, for values of $\Phi_{T}$ around $20^{\circ}$, the probability of the two states tends to be closer again, although the peaks associated with them are less distinct, probably because of the higher level of general unsteadiness caused by the separated flow from the taper. 


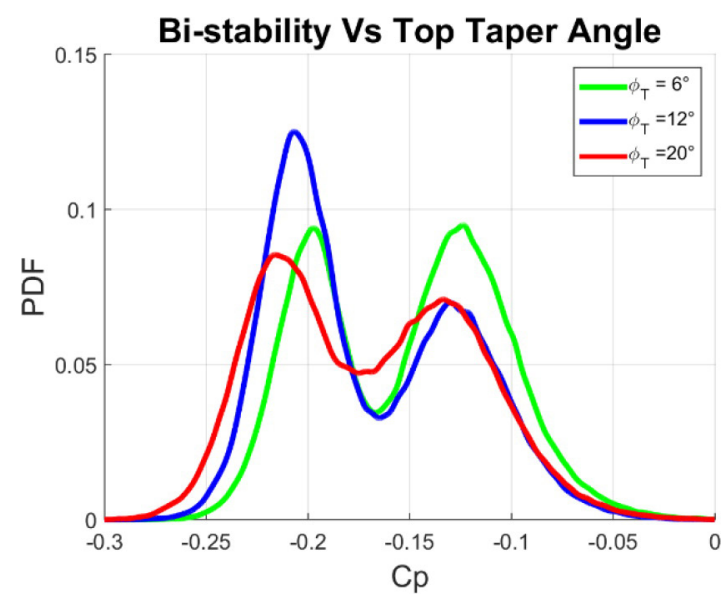

Figure 11. Probability density function of the pressure recorded by one of the tap with the highest value of $C_{P_{\text {rms }}}$ for different top taper angles.

These changes in the bi-stable behavior of the wake do not seem to significantly change the base drag, whose trend is almost the same between the two sampling times considered in the present work, with differences in the values referring to the same configuration always lower than two counts (Figure 12).

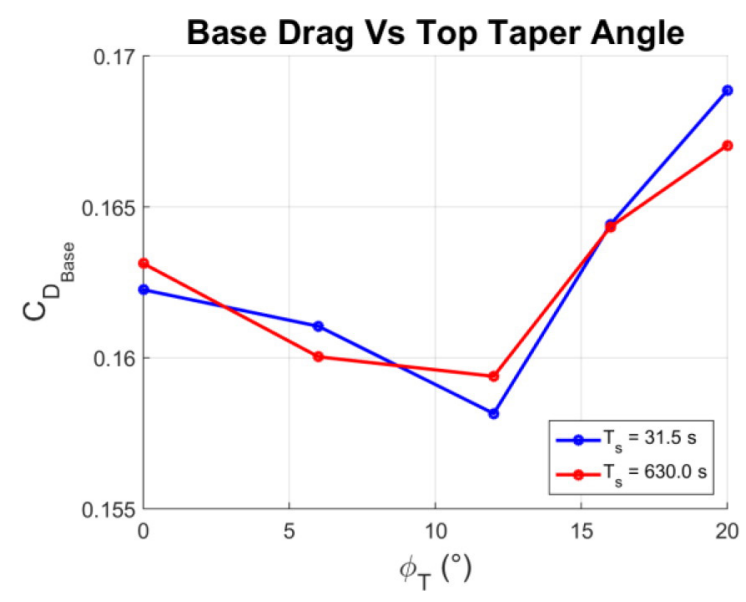

Figure 12. Values of the base pressure drag for different top taper angles estimated from pressure samples of different lengths.

\section{Bottom Taper}

A similar approach was followed in the analysis of the effects produced by the bottom taper. This time, the value of the top taper angle $\Phi_{T}$ was fixed at $0^{\circ}$ whereas the chamfer angle at the bottom trailing edge $\Phi_{B}$ was varied between $6^{\circ}$ and $20^{\circ}$. The time averaged pressure field and its fluctuations are presented in Figure 13.

Just as with the upper taper, the time averaged results (Figure

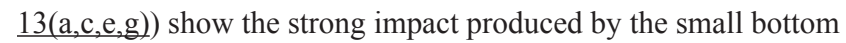
taper on the pressure distribution over the entire model base. In this case, the increase of the bottom chamfer angle results in an upwash effect that is expected to increase the size of the lower recirculation bubble and tilt the entire wake upwards, in a similar way to the bottom taper studied by Grandemange et al. [] ] for an Ahmed model.

This change in the topology of the near wake is accompanied by a growth in the size of the low pressure region close to the taper trailing edge, which promotes an increase of the base drag, until $\Phi_{B}=16^{\circ}$ (see Figure 14, long period). After this point, the low pressure region starts to shrink because the flow over the bottom slant becomes fully separated and the upwash is reduced.

Again as with the upper taper, the stall of the bottom tapered surface is clearly visible by looking at pressure fluctuation maps (Figure 13(b,d,f,h)), which show a weakening of the region with low unsteadiness described before, together with an increase of the fluctuations over the slanted surface for chamfer angles greater than $16^{\circ}$.

As the chamfer angle is increased, the bi-stable region tends to be moved towards the top trailing edge by the upwash and decreases in size as the areas of reduced unsteadiness expand, but then it starts to grow again once the flow over the slant is fully separated.
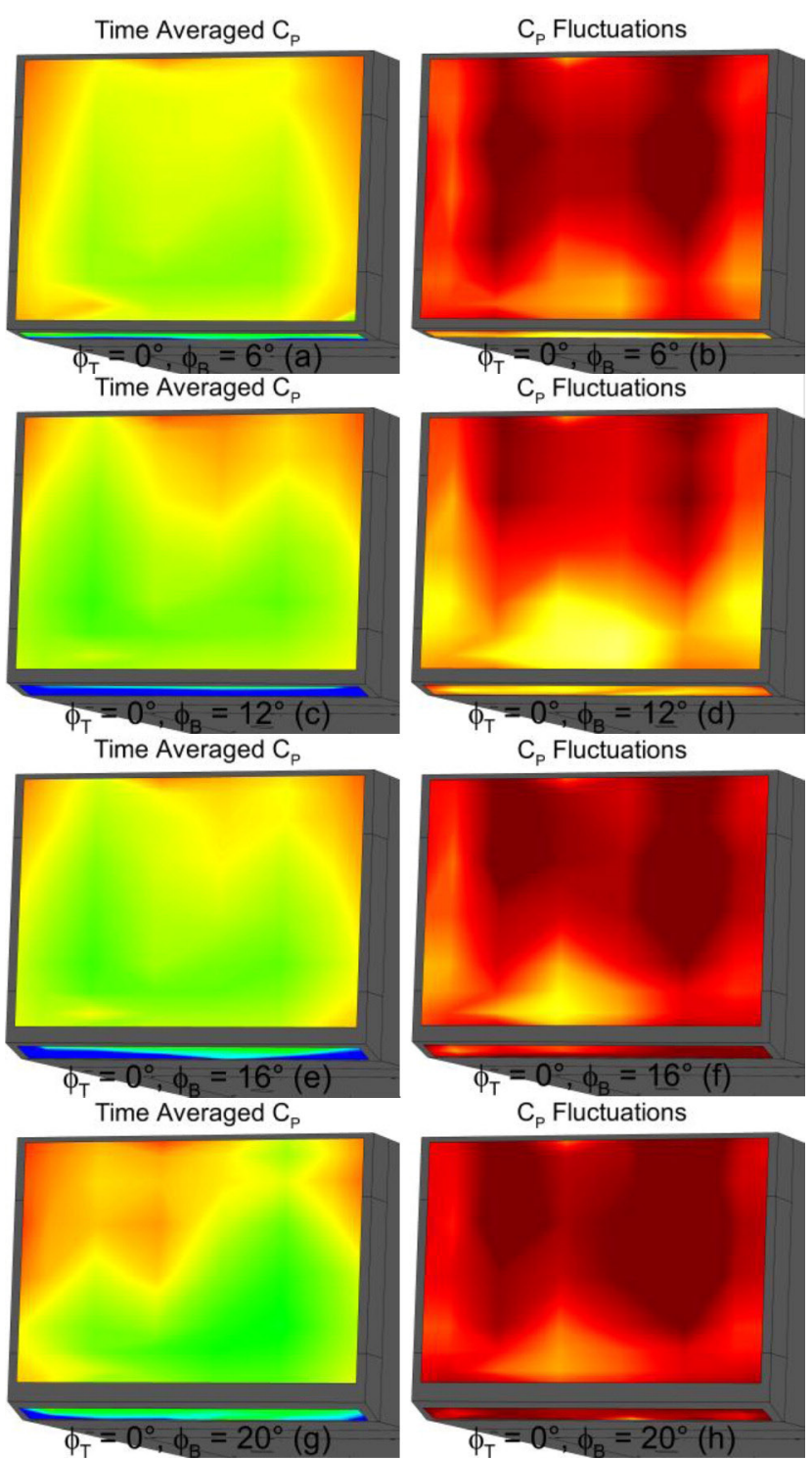

$\mathrm{C}_{\mathrm{p}}$ Fluctuations

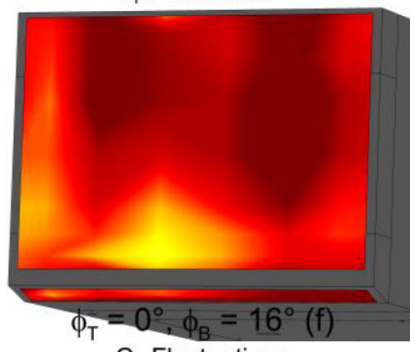

$\mathrm{C}_{\mathrm{P}}$ Fluctuations
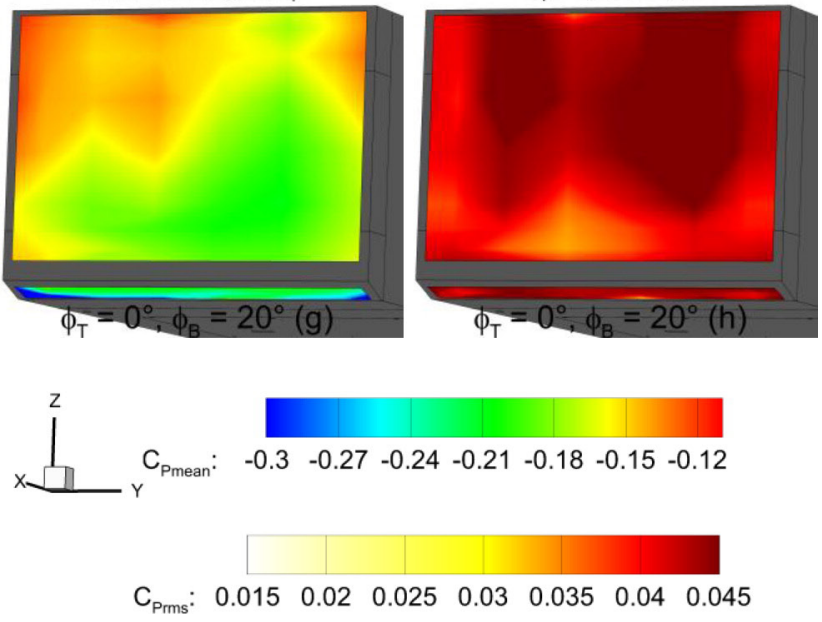

Figure 13. Time averaged and fluctuating pressure distribution over the model base for different bottom taper angles $\left(T_{S}=630.0 \mathrm{~s}\right)$. 
Compared to the upper taper, slightly larger differences are found between the base drag estimated from the data recorded with the two different sampling times Figure 14. Not only are the differences in the values obtained from the two sets of data bigger than before (with a maximum difference of almost 5 counts for the highest taper angle), but there are some differences in the overall trends as well, with the lowest and the highest values of base drag reached respectively at $\Phi_{B}$ $=6^{\circ}$ and $\Phi_{B}=12^{\circ}$ for the shortest data acquisition $\left(T_{S}=31.5 \mathrm{~s}\right)$ and at $\Phi_{B}=0^{\circ}$ and $\Phi_{B}=16^{\circ}$ for the longest sampling time $\left(T_{S}=630.0 \mathrm{~s}\right)$.

The reason of this behavior can be found in the overall higher level of unsteadiness shown by the bottom tapered surface when compared to the top. This suggests a less effective action of this taper in limiting the bi-stability, as highlighted by the presence of region of low unsteadiness that, for the same values of the chamfer angle, are usually smaller than in the previous case.

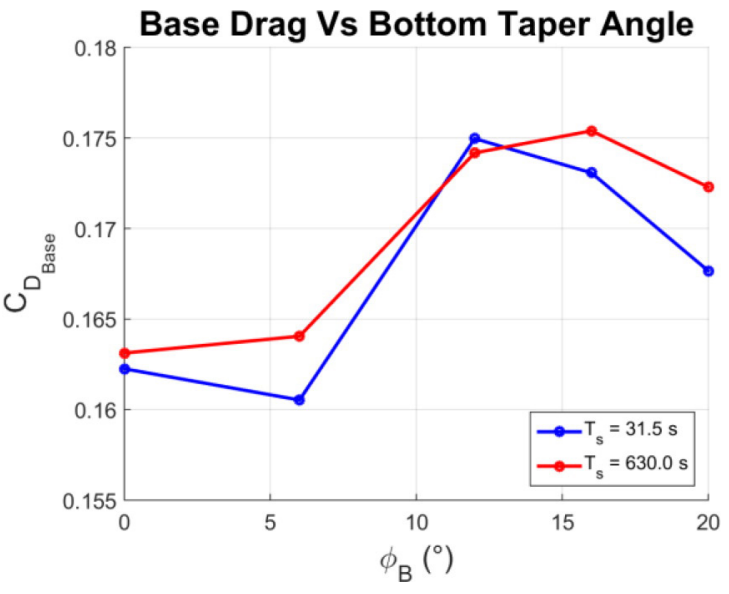

Figure 14. Values of the base pressure drag for different bottom taper angles estimated from pressure samples of different lengths.

The presence of the taper again seems to increase the selection of one of the two states, as shown by the probability density functions of the $C_{P}$ values recorded (for $\Phi_{B}=6^{\circ}, 12^{\circ}, 20^{\circ}$ ) by one of the taps placed in the region of the base characterized by the highest level of unsteadiness (Figure 15). As for the top taper, the bi-modal nature of the distribution seems to weaken as the taper angle is increased from $6^{\circ}$ to $12^{\circ}$, then becoming more visible again at $\Phi_{B}=20^{\circ}$.

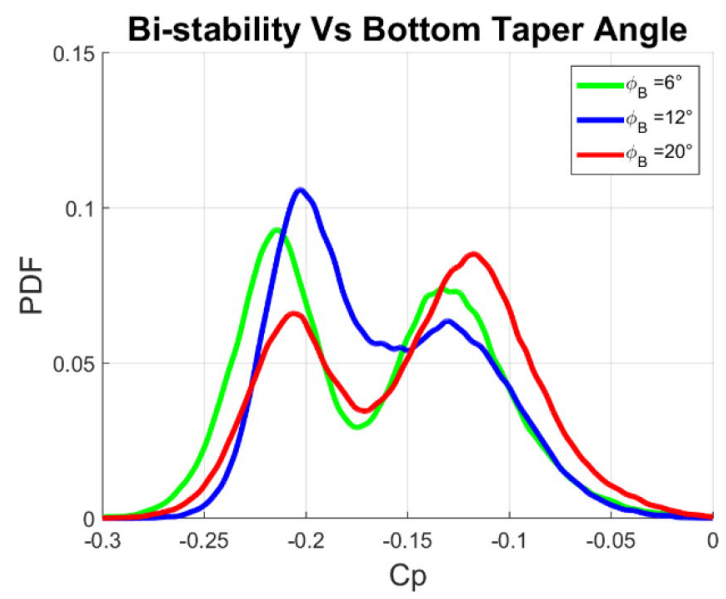

Figure 15. Probability density function of the pressure recorded by one of the tap with the highest value of $C_{P_{r m s}}$ for different bottom taper angles.
The evolution of the mean duration of the stable states $t_{s}$ with the increase of the taper angle $\Phi$ for the two cases analyzed so far can be seen in the plot reported in Figure 16. This figure highlights the presence of a similar trend between the two configurations, with the increase of the taper angle that seems to trigger a reduction of the time interval in the switch between the two states, with the minimum value (equal to $5.36 s$ in the first case and $3.42 s$ in the second case) reached for a chamfer angle of $12^{\circ}$. Beyond this angle, the duration of the stable states starts to increase again, further confirming the reinforcement of the bi-stable behavior described before, with the only exception represented by the $20^{\circ}$ top taper configuration that shows a sudden reduction of $t_{s}$, probably due to the high level of unsteadiness caused by the separated flow coming from the top slant.

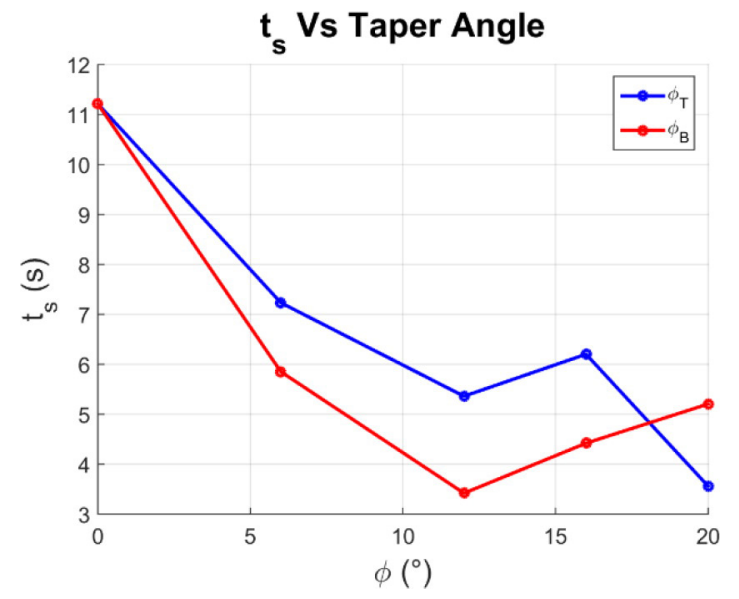

Figure 16. Evolution of the time scale $t_{s}$ of the wake bi-stability for different taper angles.

\section{Combined Tapers}

The combined effect of the horizontal tapers was then studied by applying a $16^{\circ}$ chamfer angle to the top trailing edge together with a $6^{\circ}$ taper angle on the bottom. This asymmetric configuration was chosen since it is common practice in the aerodynamic optimization process of real cars to have a diffuser angle lower than the top taper angle in order to counteract the ground effect. Moreover, this particular configuration was proven to be the one generating the lowest drag in the similar experiment carried out by Perry et al. in [11].

Looking at the time averaged results presented in Figure 17 the differences between the results obtained from the two sets of samples (recorded respectively for $31.5 s$ and $630.0 s$ ) are much smaller than in the squareback case, suggesting the presence of a more stable structure for the wake.

In particular, the low pressure region is now smaller than before and it has been split in two parts, extending mainly in the vertical direction, by a central zone with higher pressure. This suggests a more symmetric structure for the near wake, whose lobes tend to interact less with the model rear-end, allowing a better pressure recovery which results in a $C_{D_{\text {Base }}}$ equal to 0.156 , respectively $2.13 \%$ and $4.35 \%$ lower than the best results presented in Figure 12 and Figure 14 for the other configurations (at $\mathrm{T}_{\mathrm{S}}=630.0 \mathrm{~s}$ ). 


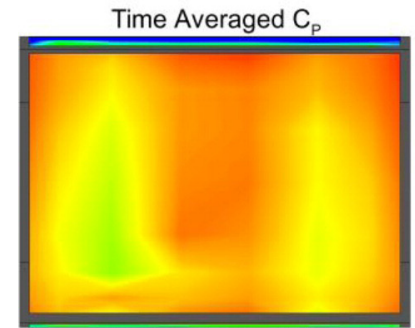

$\mathrm{T}_{\mathrm{S}}=31.5 \mathrm{~s}(\mathrm{a})$

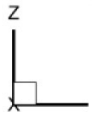

$\mathrm{C}_{\text {Pmean }}$ :

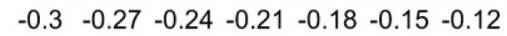

Figure 17. Time averaged pressure distribution over the model base for the configuration with $\Phi_{T}=16^{\circ}$ and $\Phi_{B}=6^{\circ}$ obtained from two different sampling times.

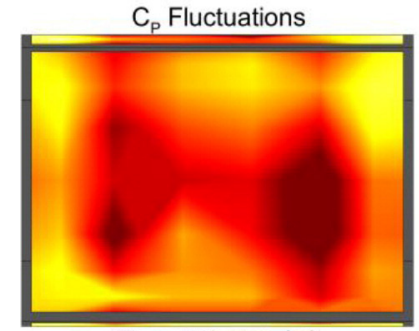

$\mathrm{T}_{\mathrm{S}}=31.5 \mathrm{~s}(\mathrm{a})$

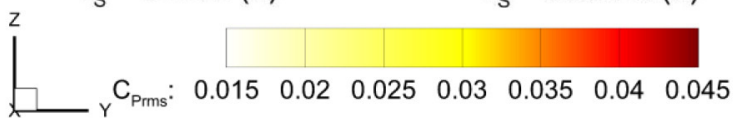

Figure 18. Fluctuating pressure distribution over the model base for the configuration with $\Phi_{T}=16^{\circ}$ and $\Phi_{B}=6^{\circ}$ and two different sampling times.

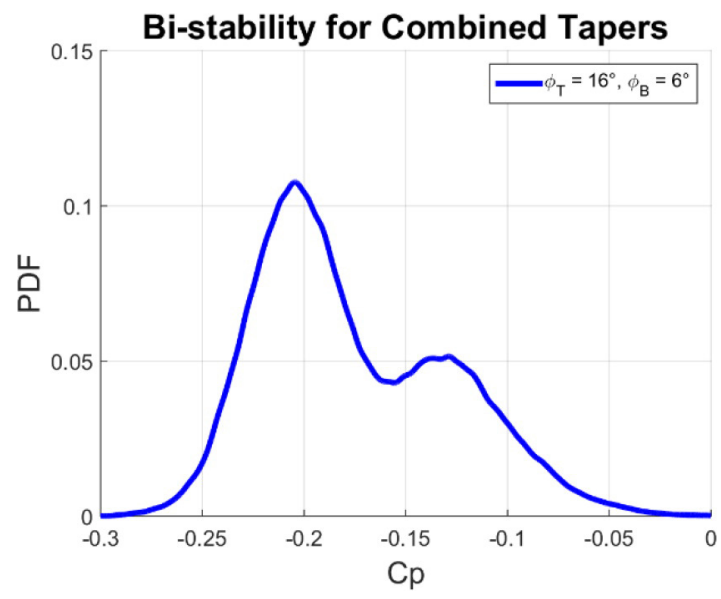

Figure 19. Probability density function of the pressure recorded by one of the taps with the highest value of $C_{P_{r m s}}$ for the configuration with $\Phi_{T}=16^{\circ}$ and $\Phi_{T}$ $=6^{\circ}$

The presence of the bi-stable zone can still be seen, as shown by the $C_{P_{r m s}}$ reported in Figure 18. Two regions of high unsteadiness are visible, located roughly between the middle of the base and the vertical edges. Nevertheless, the extent of the bi-stable zone is now reduced compared to the other configurations and it is closer to the center of the base itself. This is the result of the simultaneous action of the two tapers, as proved by the presence of the areas of relatively low unsteadiness already described for the configurations with a single chamfer. With the top and bottom taper in place, these zones are present along both the horizontal trailing edges and tend to squeeze the bi-stable area towards the center, reducing its size.
Furthermore, as in the single taper cases, the shrinking of the zone with the highest $C_{P_{r m s}}$ is accompanied by a reduction of the degree of bi-modality present (Figure 19) and here the timescale of the switching is the shortest of the configurations considered so far, being equal to $3.34 \mathrm{~s}$.

\section{Vertical Tapers}

In the second series of experiments, the effect of similar tapers applied to the model side trailing edges was investigated. The tapers were applied simultaneously to the vertical side of the model base, leaving the horizontal trailing edges squared, with the same chamfer angles $\Phi_{S}$ as considered for the horizontal tapers and an aspect ratio (based this time on the model height) equal to 6.42. The resulting time averaged $C_{P}$ and $C_{P_{r m s}}$ maps are presented in Figure 20.
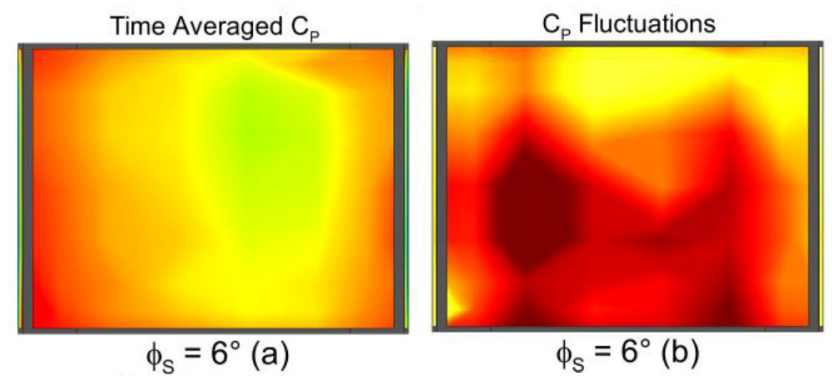

Time Averaged $\mathrm{C}_{\mathrm{p}}$

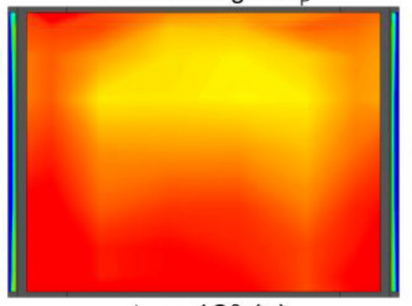

$\mathrm{C}_{\mathrm{p}}$ Fluctuations

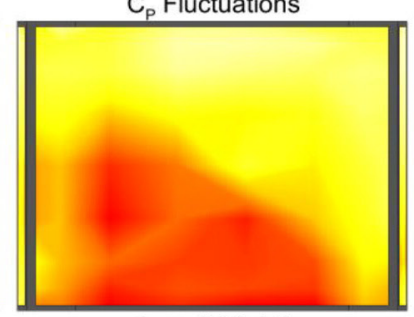

$\phi_{\mathrm{s}}=12^{\circ}(\mathrm{c})$

$\phi_{\mathrm{S}}=12^{\circ}(\mathrm{d})$

Time Averaged $\mathrm{C}_{\mathrm{p}}$

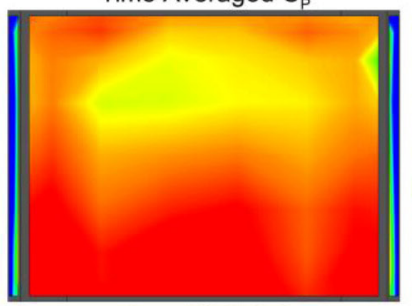

$\phi_{\mathrm{S}}=16^{\circ}(\mathrm{e})$

Time Averaged C

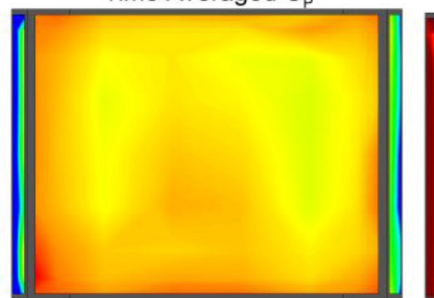

$\phi_{\mathrm{S}}=20^{\circ}(\mathrm{g})$

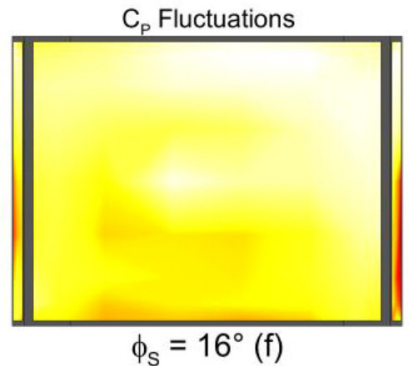

$\phi_{\mathrm{S}}=16^{\circ}(\mathrm{f})$
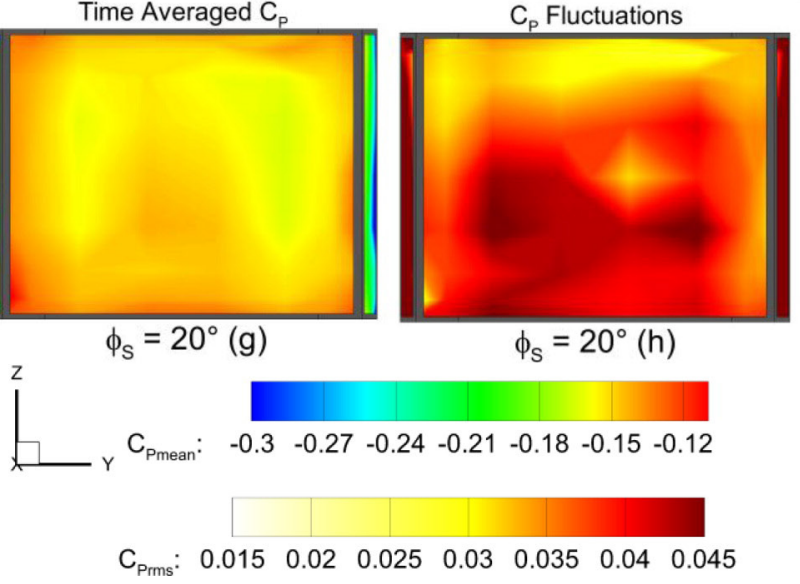

Figure 20. Time averaged and fluctuating pressure distribution over the model base for different side angles $\left(T_{S}=630.0 \mathrm{~s}\right)$. 
Starting from the time averaged results (Figure 20(a,c,e,g)), it is evident that the application of the side tapers allows a better pressure recovery. This seems to lead to a more regular shape for the near wake structure and a reduction of the interactions between the torus and the model base, as highlighted by the progressive reduction in the size of the low pressure region. The flow now entering from the sides, tends to push the recirculation zone further downstream, reducing the magnitude of the tangential velocity component acting over the model rear facing surface.

Like the horizontal case, a clear trend can be found between the taper angle and the base pressure drag (see Figure 21). In particular, a progressive decrease of the base drag, due to better pressure recovery over the model rear-end, can be observed for values of $\Phi_{S}$ between $0^{\circ}$ and $12^{\circ}$, with the minimum drag value that is $10.3 \%$ lower than the best result obtained in the previous series of tests (i.e. $\Phi_{T}=16^{\circ}$ and $\Phi_{B}=6^{\circ}$ ). This suggests a greater effectiveness of these devices in reducing the base drag compared to the horizontal tapers, in good agreement with the trend of the aerodynamic drag already recorded Perry et al. [11] for the same model.

For bigger chamfer angles, however, the low pressure zone starts to expand again, suggesting a reinforcement of the interaction between the ring vortex and the base, since the flow over the side tapers begins to separate, making these elements less effective in deflecting high speed air into the near wake. As a result, the gap between the recirculation zone and the model rear facing surface is reduced and their interaction reinforced. As with the top and bottom taper configurations, the "stall" of the slanted surface is highlighted by a sudden increase in the values of the pressure fluctuations over the tapered surface, Figure 20(h).

As a more general observation the pressure fluctuation maps (reported in Figures 20(b, d, f, h) ) are still very useful for the identification of bi-stable zone, linked to the presence of regions of high unsteadiness in both the two vertical halves of the model base. This particular distribution can be seen for the configuration with $\Phi_{S}$ $=6^{\circ}$, but then it disappears for $\Phi_{S}=12^{\circ}$ and $\Phi_{S}=16^{\circ}$. However, it turns up again for $\Phi_{S}=20^{\circ}$, when the flow over the side slants is fully separated.

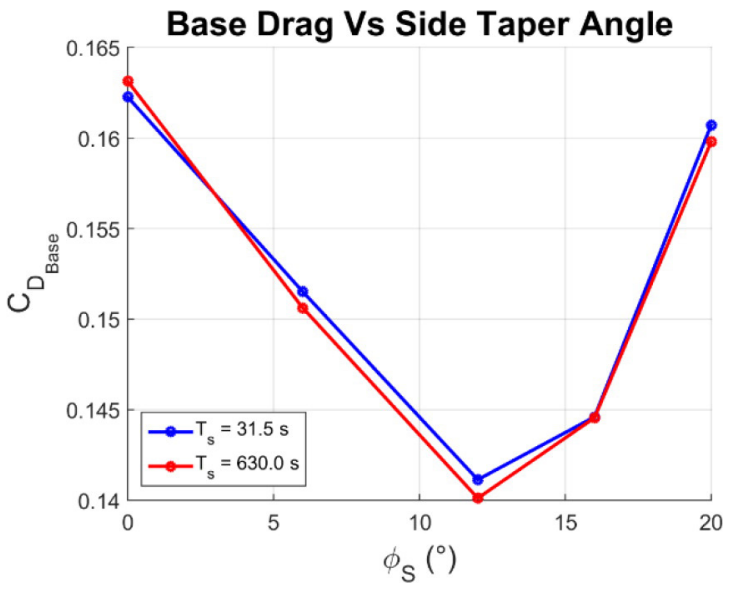

Figure 21. Values of the base pressure drag for different side taper angles estimated from pressure samples of different lengths.
As expected, a similar evolution of the bi-stable behavior can be spotted by looking at the probability density functions presented in Figure 22, related to the $C_{p}$ values recorded by one of the taps placed in the zone with the highest level of unsteadiness for three different values of the side taper angle (equal respectively to $6^{\circ}, 16^{\circ}$ and 20 $\left.{ }^{\circ}\right)$.

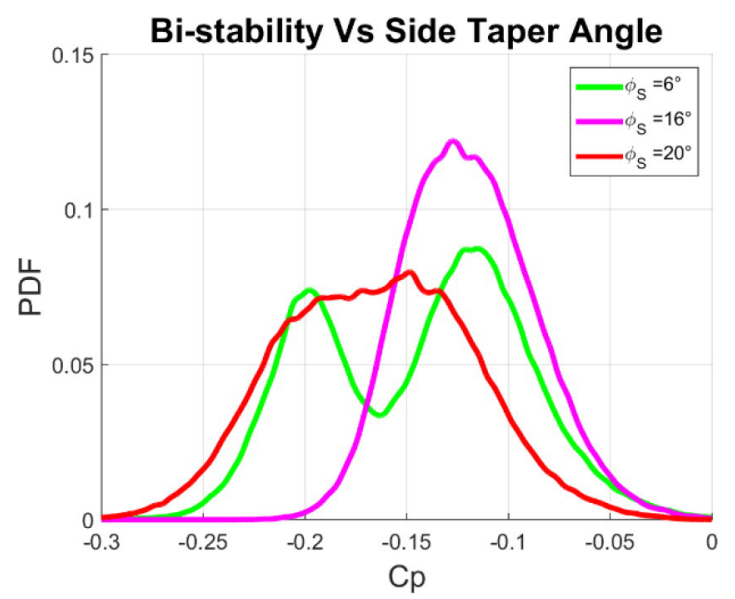

Figure 22. Probability density function of the pressure recorded by one of the taps with the highest value of $C_{P_{r m s}}$ for different side taper angles.

In particular, whereas the distribution obtained for the configuration with $\Phi_{S}=6^{\circ}$ is still characterized by a noticeable degree of bimodality with $t_{s}=6.94 \mathrm{~s}$, the curve associated with the values recorded for $\Phi_{S}=16^{\circ}$ is similar to a normal distribution, suggesting the presence of a single state rather than a continuous switch between two almost equi-probable states.
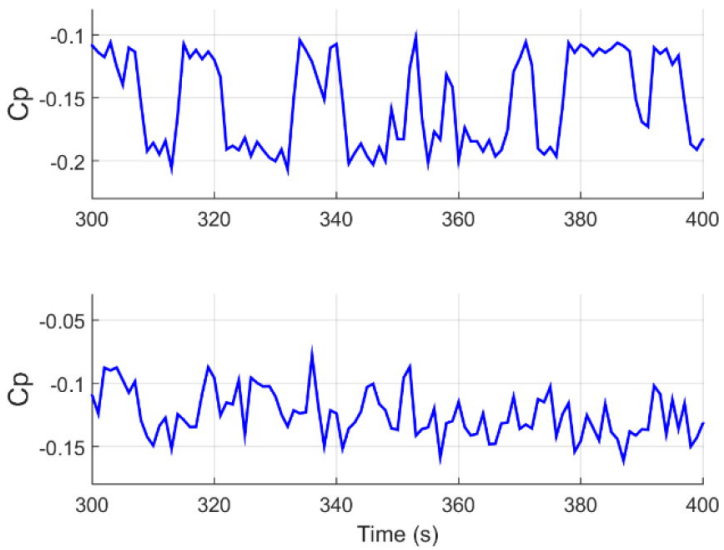

Figure 23. Comparison between the temporal trends of the $C_{p}$ values recorded by taps with the highest value of $C_{P_{r m s}}$ for $\Phi_{S}=6^{\circ}$ and $\Phi_{S}=16^{\circ}$ (data resampled at $1 \mathrm{~Hz}$ ).

The same conclusions can be drawn by comparing the temporal evolution of the $C_{p}$ values recorded by the same taps, resampled at 1 $\mathrm{Hz}$ (see Figure 23). In fact, the first configuration (with $\Phi_{S}=6^{\circ}$ ) shows a trend that is characterized by a continuous and random shift between two different values of the static pressure, in a similar way with what has already been described for the squareback case (see Figure 6), although with a shorter time scale. On the other hand, the temporal evolution of the $C_{p}$ data recorded for the second configuration (with $\Phi_{S}=16^{\circ}$ ) seems to oscillate around one single value, confirming the trend already discussed in Figure 22. 
Furthermore, the application of this particular chamfer angle seems to demonstrate that it is possible to create a perturbation in the horizontal plane which is strong enough to counteract the cross flow instabilities without forcing the symmetry of the system by using external constrains like the splitter plate suggested in [13] or vertical

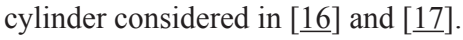

\section{Summary/Conclusions}

In the present work, the effects produced by short tapered sections applied to the trailing edge of the roof, underside and sides of a simplified passenger car model have been investigated. Surface pressure measurements were performed for the full model base for two different sampling times, equal to $31.5 s$ and $630 s$.

- For the squareback configuration a clear difference in the topology of the time averaged pressure distributions obtained from the two samples has been noted. This difference can be ascribed to the existence of a bi-stable behavior of the near wake, which consists in a continuous and random switch between two symmetry breaking states, in analogy with the results reported in [12] and [15].

- The sensitivity of bi-stability to the yaw angle was studied by performing a yaw sweep between $-0.5^{\circ}$ and $+0.5^{\circ}$. The results show that the bi-stable behavior tends to weaken as $|\Psi|$ is increased as the probability of one of the states increases. The bi-stability has almost disappeared by $|\Psi|=0.5^{\circ}$.

- The application of high aspect ratio tapers to the horizontal edges of the model has highlighted the existence of a relation between the downwash $\backslash$ upwash generated by these elements and the base drag. In particular, it has been shown that a better pressure recovery is obtained anytime a balance between these two effects is achieved, leading to a more regular shape of the recirculation region and then an increase in the amount of reverse flow normal to the model base. At the same time, the core of the vortex ring is moved downstream by the high speed flow deflected by the tapers, reducing its interaction with the model rear facing surface allowing a further improvement in the pressure recovery.

- The presence of downwash or upwash in the near wake seems to affect the bi-stability, by moving the region with high unsteadiness downwards or upwards and changing its size. It also reduces the timescale of the shift between the two states. Furthermore, the presence of a high level of downwash or upwash seems to promote the selection of one of the two states, although the bi-stability is not completely removed.

- The application of similar tapers to the vertical edges of the model base seems to yield an even bigger improvement in terms of pressure recovery, by moving the vortical torus structure further downstream and therefore reducing the size of the low pressure region. Stronger effects are also seen on the wake bistable behavior, which, not only tends to be reduced as $\Phi_{S}$ is increased, but seems to completely disappear for $\Phi_{S}=16^{\circ}$.

From the results obtained in this study it is evident that bi-stability is a phenomenon that could affect not only simplified squareback models but also real cars. The evidence that the main characteristics of the bi-stability are sensitive to the level of cross-flow entering the wake raises a question about the role played by the shear layers and longitudinal tip vortices in determining this particular instability. This aspect will be the object of the future work that will focus on the characterization of the unsteady features of wake generated by these configurations, as well as the study of the effects produced by the bistability on the aerodynamic forces acting on the entire model.

\section{References}

1. Krajnović S., and Davidson, L., "Numerical study of the flow around a bus-shaped body", Journal of Fluids Engineering 125.3: 500-509, 2003, doi: 125.3 (2003): 500-509.

2. Roumeas, M., Gilliéron, P. and Kourta, A., "Analysis and control of the near-wake flow over a square-back geometry", Computers \& Fluids 38.1: 60-70, 2009, doi:10.1016/j. compfluid.2008.01.009.

3. Ahmed, S., Ramm, G., and Faltin, G., "Some Salient Features Of The Time-Averaged Ground Vehicle Wake," SAE Technical Paper $\underline{840300}$, 1984, doi: $\underline{10.4271 / 840300}$.

4. Beaudoin, J. and Aider, J., "Drag and lift reduction of a 3D bluff body using flaps", Experiments in fluids 44.4: 491-501, 2008, doi: 10.1007/s00348-007-0392-1.

5. Pujals, G., Depardon, S., and Cossu, C., "Drag reduction of a 3D bluff body using coherent streamwise streaks", Experiments in fluids 49.5: 1085-1094, 2010, doi: 10.1007/s00348-010-0857-5.

6. Grandemange, M., Mary, A., Gohlke, M. and Cadot, O., "Effect on drag of the flow orientation at the base separation of a simplified blunt road vehicle", Experiments in fluids 54.5: 1-10, 2013, doi: 10.1007/s00348-013-1529-z.

7. Rouméas, M., Gilliéron, P. and Kourta, A., "Drag reduction by flow separation control on a car after body", International journal for numerical methods in fluids 60.11: 1222-1240, 2009, doi: $10.1002 /$ fld.1930.

8. Littlewood, R and Passmore, M., "Aerodynamic drag reduction of a simplified squareback vehicle using steady blowing.", Experiments in fluids 53.2: 519-529, 2012, doi: $10.1007 /$ s00348-012-1306-4.

9. Kim, J., Hahn, S., Kim, J., Lee, D. et al., "Active control of turbulent flow over a model vehicle for drag reduction", Journal of Turbulence 5.019: 1-12, 2004, doi: 10.1088/1468$\underline{5248 / 5 / 1 / 019}$.

10. Littlewood, R. and Passmore, M., "The Optimization of Roof Trailing Edge Geometry of a Simple Square-Back.," SAE Technical Paper 2010-01-0510, 2010, doi:10.4271/2010-01$\underline{0510}$.

11. Perry, A., Passmore, M., and Finney, A., "Influence of Short Rear End tapers on the Base Pressure of a Simplified Vehicle.," SAE Int. J. Passeng. Cars - Mech. Syst. 8(1):317-327, 2015, doi: $10.4271 / 2015-01-1560$.

12. Grandemange, M., Gohlke, M. and Cadot, O., "Turbulent wake past a three-dimensional blunt body. Part 1. Global modes and bi-stability", Journal of Fluid Mechanics 722: 51-84, 2013, doi: http://dx.doi.org/10.1017/jfm.2013.83.

13. Grandemange, M., Gohlke, M. and Cadot, O., "Bi-stability in the turbulent wake past parallelepiped bodies with various aspect ratios and wall effects", Physics of Fluids (1994-present) 25. 9: 095103, 2013, doi :http://dx.doi.org/10.1063/1.4820372. 
14. Herry, B. B., Keirsbulck, L., Labraga, L. and Paquet, J.B., "Flow bistability downstream of three-dimensional double backward facing steps at zero-degree sideslip", Journal of Fluids Engineering 133. 5: 054501, 2011, doi: 10.1115/1.4004037.

15. Volpe, R., Devinant, P. and Kourta, A., "Experimental characterization of the unsteady natural wake of the fullscale square back Ahmed body: flow bi-stability and spectral analysis", Experiments in Fluids 56.5: 1-22, 2015, doi: $10.1007 /$ s00348-015-1972-0.

16. Grandemange, M., Cadot, O., Courbois, A., Herbert, V. et al., "A study of wake effects on the drag of Ahmed's squareback model at the industrial scale", Journal of Wind Engineering and Industrial Aerodynamics 145: 282-291, 2015, doi: 10.1016/j. jweia.2015.03.004.

17. Grandemange, M., Gohlke, M. and Cadot, O., "Turbulent wake past a three-dimensional blunt body. Part 2. Experimental sensitivity analysis", Journal of Fluid Mechanics 752: 439-461, 2014 doi: http://dx.doi.org/10.1017/jfm.2014.345.

18. Sims-Williams, D., Marwood, D., and Sprot, A., "Links between Notchback Geometry, Aerodynamic Drag, Flow Asymmetry and Unsteady Wake Structure," SAE Int. J. Passeng. Cars - Mech. Syst. 4(1):156-165, 2011, doi:10.4271/2011-01-0166.

19. Krajnovic, S. and Minelli, G., "Les Investigation of the Asymmetry in the Wake of a Generic Vehicle Body.", 4th International Conference on Jets, Wakes and Separated Flows, ICJWSF2013 IMECE 2013, September 17-21, 2013, Nagoya, Japan.

20. Kawakami, M., Murata, O., and Maeda, K., "Improvement in Vehicle Motion Performance by Suppression of Aerodynamic Load Fluctuations," SAE Int. J. Passeng. Cars - Mech. Syst. 8(1):205-216, 2015, doi:10.4271/2015-01-1537.

21. Johl, G., Passmore, M. and Render, P., "Design methodology and performance of an indraft wind tunnel", Aeronautical Journal 108.1087: 465-473, 2004.

22. Cooper, K., Bertenyi, T., Dutil, G., Syms, J. et al., "The Aerodynamic Performance of Automotive Underbody Diffusers," SAE Technical Paper 980030, 1998, doi: $10.4271 / 980030$.

23. Sims-Williams, D. and Dominy, R., "Experimental Investigation into Unsteadiness and Instability in Passenger Car Aerodynamics," SAE Technical Paper 980391, 1998, doi:10.4271/980391.

24. Wood, D., Passmore, M., and Perry, A., "Experimental Data for the Validation of Numerical Methods - SAE Reference Notchback Model," SAE Int. J. Passeng. Cars - Mech. Syst. 7(1):145-154, 2014, doi:10.4271/2014-01-0590.
25. Strachan, R. K., Knowles, K. and Lawson, N. J. "The vortex structure behind an Ahmed reference model in the presence of a moving ground plane", Experiments in fluids 42.5: 659-669, 2007, doi: 10.1007/s00348-007-0270-x.

26. Littlewood, R., Passmore, M., and Wood, D., "An Investigation into the Wake Structure of Square Back Vehicles and the Effect of Structure Modification on Resultant Vehicle Forces," SAE Int. J. Engines 4(2):2629-2637, 2011, doi:10.4271/2011-37-0015.

27. Khalighi, B., Chen, K. and Iaccarino, G., "Unsteady aerodynamic flow investigation around a simplified square-back road vehicle with drag reduction devices", Journal of Fluids Engineering 134.6: 061101, 2012, doi: 10.1115/1.4006643.

28. Howell, J., Passmore, M., and Tuplin, S., "Aerodynamic Drag Reduction on a Simple Car-Like Shape with Rear Upper Body Taper," SAE Int. J. Passeng. Cars - Mech. Syst. 6(1):52-60, 2013, doi: $10.4271 / 2013-01-0462$.

\section{Contact Information}

Giancarlo Pavia

G.Pavia@1boro.ac.uk

Martin Passmore

M.A.Passmore@lboro.ac.uk

\section{Acknowledgments}

The authors would like to thank Jaguar Land Rover and the EPSRC for their financial support. Thanks are also due to Mr. David Cooper and Mr. Nigel Lines for their excellent work in manufacturing the model and keeping the test facility always in optimal conditions.

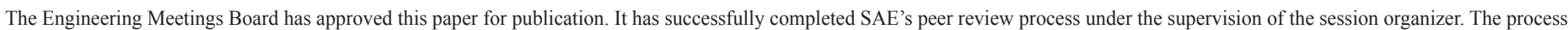
requires a minimum of three (3) reviews by industry experts.

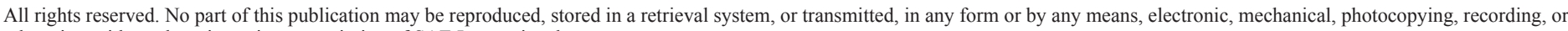
otherwise, without the prior written permission of SAE International.

Positions and opinions advanced in this paper are those of the author(s) and not necessarily those of SAE International. The author is solely responsible for the content of the paper.

ISSN 0148-7191

http://papers.sae.org/2016-01-1590 